\title{
Sex Determination from the Morphometry of the Foramen Magnum in Benin: Potential Forensic Identification Tool
}

\author{
Yekpe Ahouansou Patricia ${ }^{1,2,{ }^{*}, \text { Savi de Tove Kofi-Mensa }}{ }^{3}$, Bigot Cep ${ }^{2,4}$, Adjadohoun Sbmg ${ }^{1,2}$, \\ Savi de Tove Jean-Louis ${ }^{1}$, Adjovi Boris ${ }^{1}$, Biaou Olivier ${ }^{1,2}$, Boco Vicentia ${ }^{1,2}$ \\ ${ }^{1}$ Department of Radiology and Medical Imaging, National Teaching University Hospital Hubert Koutoukou Maga (CNHU-HKM), Cotonou, \\ Benin Republic \\ ${ }^{2}$ University of Abomey-Calavi, Faculty of Health Sciences, Abomey-Calavi, Benin Republic \\ ${ }^{3}$ Radiology Department Parakou, Teaching University Hospital of Borgou Department, Parakou, Benin Republic \\ ${ }^{4}$ Forensic Medicine Unit, Internal Medicine, National Teaching University Hospital Hubert Koutoukou Maga (CNHU-HKM), Cotonou, \\ Benin Republic
}

\section{Email address: \\ yfrida_pat@yahoo.fr(Y. A. Patricia) \\ ${ }^{*}$ Corresponding author}

\section{To cite this article:}

Yekpe Ahouansou Patricia, Savi de Tove Kofi-Mensa, Bigot Cep, Adjadohoun Sbmg, Savi de Tove Jean-Louis, Adjovi Boris, Biaou Olivier, Boco Vicentia. Sex Determination from the Morphometry of the Foramen Magnum in Benin: Potential Forensic Identification Tool. International Journal of Medical Imaging. Vol. 8, No. 4, 2020, pp. 84-88. doi: 10.11648/j.ijmi.20200804.13

Received: October 6, 2020; Accepted: October 21, 2020; Published: October 30, 2020

\begin{abstract}
Background: previous studies had concluded that studying the measurements of the foramen magnum could enable sex determination with good reliability for forensic identification issue. The reliability of identification methods based on foramen magnum measurements are related to natives populations. Objective: he objective of this study was to assess the value of the measurements' use of the foramen magnum in the identification of the sex with a view to exploitation in forensic medicine at the local level. Methods: The antero-posterior and latero-lateral diameters as well as the area of the foramen magnum were measured and calculated on a series of 200 cranial scans (114 men and 84 women). The distribution of measurements was compared by sex. The collected data was subjected to binary logistic regression analysis. Results: The values of the measurements of the foramen magnum of the men are significantly higher than those of the women. Binary logistic regression performed from anteroposterior diameter or areas correctly predicted gender in 64 to $66 \%$ of cases. When the regression is based on the latero-lateral diameter alone, 56.8\% of individuals are well classified. Conclusion: Sexual dimorphism is pronounced at the level of FM morphometry. Measurements of the foramen magnum can be used to identify sex in a forensic context in Benin. However, its use should preferably be done as a confirmatory test or in situations where the occipital bone is the only structure of the skull that is complete.
\end{abstract}

Keywords: Foramen Magnum, Scanner, Forensic Identification, Sex, Benin

\section{Introduction}

The discovery of human remains requires the opening of legal proceedings which must lead to the identification of the deceased and the determination of the cause of death. The forensic investigation requires the assistance of the forensic pathologist or anthropologist who will be assigned the task of identifying the human remains. Identification requires that one can at least be able to determine the biological sex. The determination of sex is based on the study of the skeleton [1].
Indeed, between men and women there are morphological and structural differences in the skeleton. This is sexual dimorphism [1]. When the skeleton is complete, the reliability of the predictive tools for sex is close to $100 \%$. The sex determination methods based on the study of the entire skull and pelvis are the most reliable [2]. But very often, the skeleton to be identified is incomplete. This is the case when the body has been subjected to flames, an explosion or when there has been an attempt to destroy or conceal the body. In these cases, the determination of the sex 
involves anthropometric methods. These methods are supported by the fact that there would be differences in statistical distributions between the measurements of the bone structures of men and women [3]. Thus, the long bones of men would be relatively longer than those of women. The precision of these methods being very influenced by ancestrality (ethical origin), is important to establish specific mathematical tools for each population $[4,5]$.

The foramen magnum (FM) is a bony orifice connecting the base of the skull and the neck. It gives passage to noble vasculo-nervous structures. This anatomical structure is of major interest in forensic identification. The occipital bone is strong and relatively well protected from the situation [6].

Previous studies had concluded that studying the measurements of the foramen magnum could enable sex determination with different sensitivities but all higher than $65 \%$ [7, 8-10]. The reference material in these studies was either bone collections or series of CT images. In the West Africa countries, particularly in Benin, osteotheces are scarce. In fact, very few remains are offered to laboratories there and the handling of human remains is very poorly perceived in the collective unconscious [11]. CT images are therefore the most accessible tool. In Benin, the CT scan of the skull is the most performed CT scan.

In the present preliminary study, various dimensions of the foramen magnum were investigated using CT images to assess levels of sexual dimorphism in the population of Benin for exploitation in forensic medicine. Its objective was to make sure that there was a difference between the measurements of the foramen magnum of men and women, and to see if these differences could be used to correctly classify individuals according to their biological sex.

\section{Methods}

This was an analytical and descriptive study with prospective collection which took place over a period of 7 months (from January 1 to July 31, 2019) in the CT unit of the National Teaching university Hospital Hubert Koutoukou Maga (CNHU-HKM) of Cotonou in Benin. We had conducted a comprehensive census of normal cranioencephalic scans of subjects aged 18 years old and above, performed during the study period. Scans that did not cover the entire foramen magnum were excluded. The CT images were obtained using the Emotion Siemens Somaton 16-bar scanner started up in December 2013 and studied using the Merge eFilm Workstation (MEW) 4.2.0 software. The images were studied in bone windows on axial slices and on multiplanar reconstructions (MPR). The morphology of the foramen magnum was studied using the classification of Murshed et al. [12, 13]. The morphometry was obtained using the ruler tool of the MEW software. The measurements taken were the large diameter (D) or antero-posterior diameter and the small diameter (d) or latero-lateral diameter (Figure 1). These were the largest diameter on the anteroposterior visual scale and the largest latero-lateral diameter of the foramen magnum, respectively, measured on axial slices.

The area of the foramen magnum was also calculated according to the formulas proposed by Radinsky's and Teixeria [14].

Radinsky formula: $A=1 / 4 \times \pi \times D \times d$

Teixeria's formula: $A=\pi \times((D \times d) / 4) 2$

The measurements were all taken by the same previously trained operator. At the beginning of the study a series of 12 scanners were selected. The operator took measurements twice and 5 days apart to ensure that there was good intraoperator reproducibility.

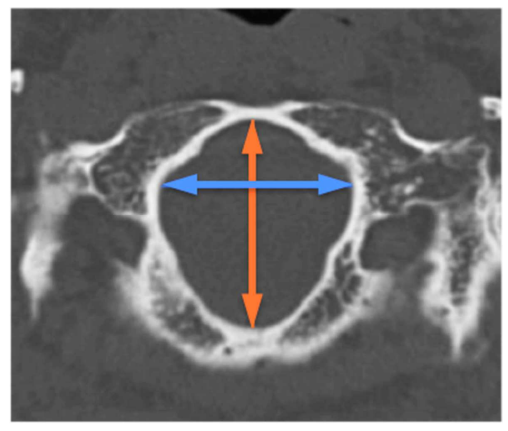

Figure 1. Axial section through a bone window showing the measurements, large diameter (orange) and small diameter (blue) of the foramen magnum (Source: Department of Radiology of CNHU-HKM).

Data analysis was performed using SPSS version 25 software. Frequency comparison was performed using $\mathrm{Chi}^{2}$ tests or Fischer's exact test. The mean comparison test was done using Student's test. A binary logistic regression was performed with each diameter and with the area of the foramen magnum. The ability of each model to correctly predict the sex of individuals in the sample was also calculated.

\section{Results}

Of the 200 craniofacial scanners, there were 114 male scanners and 86 female scanners. The average age was 51.4 $+/-16.6$ years old with extremes of 18 and 90 years old.

The frequencies of the different forms of the foramen magnum observed in our sample are presented in Table 1. The oval $(27.0 \%)$, tetragonal $(24.5 \%)$ and hexagonal $(20.5 \%)$ forms were the most represented in women and men (Figures 2,3 , and 4). There was no significant difference between the 2 groups.

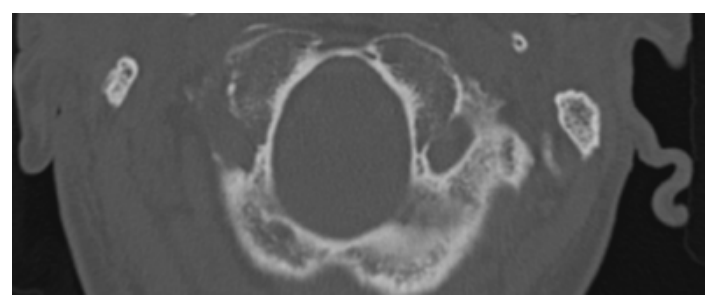

Figure 2. Axial section through a bone window showing an oval-shaped foramen magnum (Source: Radiology Department of CNHU-HKM). 


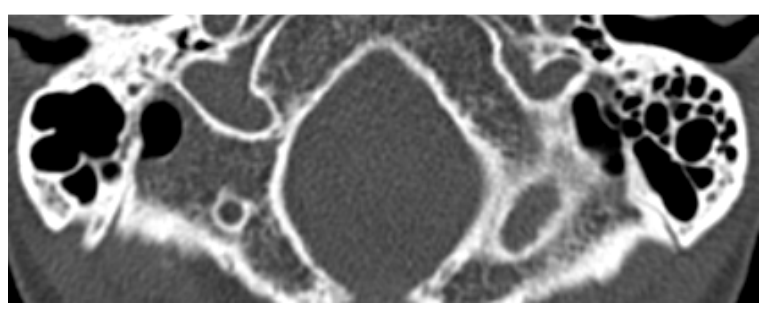

Figure 3. Axial section through a bone window showing a tetragonal-shaped foramen magnum (Source: Radiology Department of the CNHU).

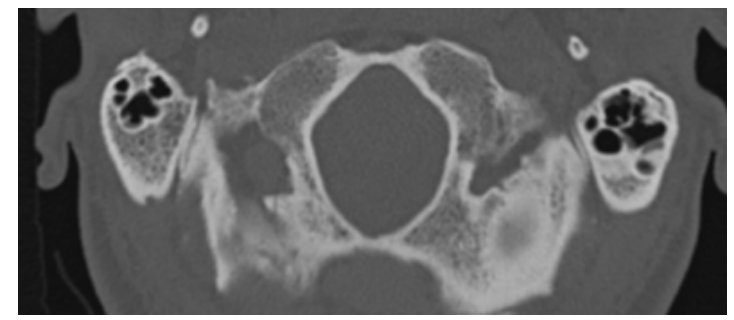

Figure 4. Axial section through a bone window showing a hexagonal foramen magnum ((Source: Radiology Department of CNHU-HKM).
Table 2 presents the comparative statistical distributions of the diameters and areas of the foramen magnum of males and females. The large and small diameter of the foramen magnum in males are relatively larger than those in females. The same trend is observed at the area level. The areas calculated with Teixeria's formula were relatively smaller than those calculated with Radinsky's formula.

Table 1. Distribution of the morphology of the foramen magnum according to the classification used by Murshed et al.

\begin{tabular}{|c|c|c|c|c|c|c|c|}
\hline \multirow[b]{2}{*}{ Formes } & \multicolumn{2}{|c|}{ Man } & \multicolumn{2}{|c|}{ Woman } & \multicolumn{2}{|c|}{ Total } & \multirow[t]{2}{*}{$\mathbf{P}$} \\
\hline & $\mathbf{n}$ & $\%$ & $\mathbf{n}$ & $\%$ & $\mathbf{n}$ & $\%$ & \\
\hline Ovoide & 13 & 11.40 & 13 & 15.12 & 26 & 13.00 & \\
\hline Oval & 35 & 30.70 & 18 & 20.93 & 53 & 26.50 & \\
\hline Egg & 5 & 4.39 & 8 & 9.30 & 13 & 6.50 & \\
\hline Tétragonal & 18 & 15.79 & 20 & 23.26 & 38 & 19.00 & \\
\hline Pentagonal & 6 & 5.26 & 4 & 4.65 & 10 & 5.00 & \\
\hline Hexagonal & 30 & 26.32 & 19 & 22.09 & 49 & 24.50 & \\
\hline Irregular type A & 4 & 3.51 & 1 & 1.16 & 5 & 2.50 & \\
\hline Irregular type B & 3 & 2.63 & 3 & 3.49 & 6 & 3.00 & 0.48 \\
\hline
\end{tabular}

Table 2. Measurements and Areas of Foramen magnum by sex.

\begin{tabular}{lllllll}
\hline & women & & & Men & \\
\hline & Extreme & Average & $\begin{array}{l}\text { standard } \\
\text { deviation }\end{array}$ & Extremes & $\begin{array}{l}\text { standard } \\
\text { deviation }\end{array}$ & p-value \\
\hline Large diameter $(\mathrm{mm})$ & $29-44$ & 35.42 & 3.1 & $31-50$ & 37.9 & 3.3 \\
Small diameter $(\mathrm{mm})$ & $21-38$ & 30.45 & 3.3 & $17-44$ & 31.8 & 4.2 \\
Area (F. Radinsky) $(\mathrm{mm})_{2}$ & $544-1243$ & 848.8 & 133.6 & $414-1727$ & 956.7 & 0.019 \\
Area (F. Teixera) $(\mathrm{mm})_{2}$ & $572-1256$ & 856.6 & 133.2 & $452-1734$ & 965.0 & 208.9 \\
\hline
\end{tabular}

Equations for predicting sex from diameters and areas were obtained by logical regression. The parameters of these equations are shown in Table 3. The male correct prediction rate is higher than $75 \%$ for each of the 4 models. On the other hand, among women, only the logistic regression model based on the large diameter can correctly classify more than one in two women (more than $50 \%$ of women). This model also has the best overall correct classification rate $(66 \%)$.

Table 3. Results of the binary logistic regression making it possible to predict the sex from the measurements of the foramen magnum.

\begin{tabular}{|c|c|c|c|c|c|c|c|c|}
\hline \multicolumn{5}{|c|}{ logistic regression } & \multicolumn{4}{|c|}{ Correct prediction rate (\%) } \\
\hline Variables & Coefficient (B) & S. E & Wald & $\operatorname{Exp}(B)$ & p-value & Woman & Man & Global \\
\hline Large diameter (mm) & 0.228 & 0.050 & 20.485 & 1.253 & 0.001 & 53.5 & 75.4 & 66.0 \\
\hline Constant & -1.929 & 0.499 & 14.967 & 0.145 & 0.001 & & & \\
\hline Small diameter (mm) & 0.091 & 0.039 & 5.554 & 1.095 & 0.018 & 26.7 & 79.6 & 56.8 \\
\hline Constant & -2.570 & 1.210 & 4.509 & 0.077 & 0.034 & & & \\
\hline Area (F. Radinsky) $(\mathrm{mm})_{2}$ & 0.003 & 0.001 & 11.800 & 1.003 & 0.001 & 43.0 & 79.8 & 64.0 \\
\hline Constant & -2.535 & 0.826 & 9.424 & 0.079 & 0.002 & & & \\
\hline Constant & -2796 & 0.858 & 10.629 & 0.061 & 0.001 & & & \\
\hline
\end{tabular}

\section{Discussion}

The present study investigated the morphology and morphometry of the foramen magnum in a sample of the Beninese population. It was looking to see if it was possible to confidently predict sex from the shape and measurements of the foramen magnum measured on CT images. Analysis of these results confirms that there is indeed a sexual dimorphism at the level of the foramen magnum. This dimorphism affects the diameters and area of the foramen magnum. It excludes form. This dimorphism can be exploited to determine gender with relative reliability.
In our sample, FMs with an oval $(27.0 \%)$, tetragonal $(24.5 \%)$ and hexagonal $(20.5 \%)$ shape are the most represented in the 2 groups. There was no significant difference between men and women $(p=0.48)$. This lack of shape-based dimorphism has been reported in the rare studies carried out on the subject in black Africa, particularly in Nigeria [15, 16], Kenya [17] and South Africa [18]. In most studies of morphology, the tetragon forms figures prominently. At Loyal $\mathrm{P}$ in Kenya, out of 10 subjects it is present in more than 6, i.e. 3 times more than in our sample. The descriptors used to describe the shape of FM may appear ambiguous and subjective. This subjectivity may explain the variability of the frequencies of the forms from one study to 
another [19].

The studies conducted by Edwards et al. [20], Raghavendra et al [9], Ilguy et al [21], and Burdan et al. [22] all showed that the antero-posterior FM diameter was significantly larger than the latero-lateral diameter and that the FM diameters of men were significantly larger than that of women. Our results are similar.

Table 4 compares the FM measurements observed in our series with those of other studies carried out in black Africa. It shows great variability from one population to another. The values observed in our series are very close to those observed in Nigeria. This is explained by the geographical, cultural and genetic proximity that exists between the black populations of the two countries.

Table 4. Comparison of the diameters of the foramen magnum of our study with those of other studies conducted in black Africa.

\begin{tabular}{|c|c|c|c|c|}
\hline Authors & $\begin{array}{l}\text { Loyal P et al } \\
(17)\end{array}$ & $\begin{array}{l}\text { Ukoba et al } \\
\text { (15) }\end{array}$ & $\begin{array}{l}\text { Moodley et } \\
\text { al (18) }\end{array}$ & Our study \\
\hline Country & Kenya & Nigeria & South Africa & Benin \\
\hline $\mathrm{M} / \mathrm{W}^{*}$ & $138 / 64$ & $90 / 10$ & $93 / 57$ & $114 / 86$ \\
\hline Material & Skeleton & Skeleton & Scanner & Scanner \\
\hline \multicolumn{5}{|c|}{ Large diameter } \\
\hline Man & $40.0 \pm 6.5$ & $36.26 \pm 2.39$ & $35.66 \pm 2.77$ & $37.9 \pm 3.3$ \\
\hline $\begin{array}{l}\text { Woman } \\
\text { small diameter }\end{array}$ & $38.5 \pm 6.5$ & $34.39 \pm 8.85$ & $34.32 \pm 2.48$ & $35.42 \pm 3.1$ \\
\hline Man & $38.00 \pm 7.0$ & $30.09 \pm 2.58$ & $29.47 \pm 2.16$ & $31.8 \pm 4.2$ \\
\hline Woman & $28.0 \pm 7.0$ & $28.16 \pm 1.99$ & $27.86 \pm 2.31$ & $30.45 \pm 3.3$ \\
\hline
\end{tabular}

M/W: Man/Woman.

In our study, the binary logistic regressions used to predict sex from each of the diameters or area of the foramen magnum confirms the thesis of sexual dimorphism. Confusion matrices showed that the anteroposterior diameter was the most reliable variable to predict sex with a correct prediction rate of $66 \%$. The FM areas had a slightly lower reliability. The reliability of the sex estimate from the latero-lateral diameter was just $56 \%$. Our results are similar to those studies conducted in Europe [2, $20,23]$. In these studies, the overall performances vary between 55 and $68 \%$ of correct predictions and the anteroposterior diameter is the variable which presents the best predictive power of sex. Other authors have observed better performance. Raghavendra et al. using logistic regression were able to correctly predict the sex from the anteroposterior diameter in $86.5 \%$ of cases against $65.4 \%$ using the laterolateral diameter [9]. Uthman using discriminant analysis reaches an accurate prediction rate of $69.3 \%$ with the same variable [13]. Whatever the model, the performance obtained with the foramen magnum remains inferior to that obtained with a complete skull $[24,25]$. In view of the performance of the models that we obtained by logistic regression, we can retain that from the measurements of the FM, only the anteroposterior diameter can be used to predict the sex. Its use should mainly be done as supporting findings.

\section{Conclusion}

The sexual dimorphism is indeed pronounced at the level of the measurements with the scanner of the foramen magnum in a sample of the population of Benin. This study confirms the fact that the sexual dysmorphism of foramen magnum can be validly exploited in the context of forensic identification. Predicting's tools obtain with binary logistic regression should be tested with anthropometric materials.

However, its use should preferably be done as a confirmatory test or in situations where the occipital bone is the only structure of the skull that is complete.

\section{Declaration of Interest}

The authors declare that there is no conflict of interest. in connection with this study.

\section{References}

[1] Krishan K, Chatterjee PM, Kanchan T, Kaur S, Baryah N, Singh RK. A review of sex estimation techniques during examination of skeletal remains in forensic anthropology casework. Forensic Sci Int. 2016; 261: 165. e1-165. e8.

[2] Cappella A, Gibelli D, Vitale A, Zago M, Dolci C, Sforza C, et al. Preliminary study on sexual dimorphism of metric traits of cranium and mandible in a modern Italian skeletal population and review of population literature. Leg Med. 2020; 44: 101695 .

[3] Quatrehomme G, Radoman I, Nogueira L, du Jardin P, Alunni V. Sex determination using the DSP (probabilistic sex diagnosis) method on the coxal bone: Efficiency of method according to number of available variables. Forensic Sci Int. 2017; 272: 190-3.

[4] Lee U-Y, Kim I-B, Kwak D-S. Sex determination using discriminant analysis of upper and lower extremity bones: New approach using the volume and surface area of digital model. Forensic Sci Int. 2015; 253: 135. e1-135. e4.

[5] Ubelaker DH, DeGaglia CM. Population variation in skeletal sexual dimorphism. Forensic Sci Int. 2017; 278: 407. e1-407. e7.

[6] Degno S, Abrha M, Asmare Y, Muche A. Anatomical Variation in Morphometry and Morphology of the Foramen Magnum and Occipital Condyle in Dried Adult Skulls: J Craniofac Surg. 2019; 30 (1): 256-9.

[7] Schmittbuhl M, Escolle F, Le minor JM. Variations de taille et de forme du foramen magnum dans l'espèce humaine': caractérisation et analyse d'un polymorphisme. Morphologie. 2004; 88 (281): 76.

[8] Varlam H, Antohe I, Chistol R-O, Antohe DS. L'étude morphologique et morphométrique du foramen magnum et de la région avoisinante. Morphologie. 2006; 90 (289): 107-8.

[9] Raghavendra Babu YP, Kanchan T, Attiku Y, Dixit PN, Kotian MS. Sex estimation from foramen magnum dimensions in an Indian population. J Forensic Leg Med. 2012; 19 (3): 162-7.

[10] Günay Y, Altinkök M. The value of the size of foramen magnum in sex determination. J Clin Forensic Med. 2000; 7 (3): 147-9. 
[11] Charlier P, Brun L, De la Grandmaison G, Hervé C. Medical students from Parakou (Benin) and West-African traditional beliefs on death and cadavers. Afr Health Sci. 2013; 12 (4). 74-85.

[12] Murshed KA, Çiçekcibaşi AE, Tuncer I. Morphometric evaluation of the foramen magnum and variations in its shape: A study on computerized tomographic images of normal adults. Turk J Med Sci. 2003; 33 (5): 301-6.

[13] Uthman A, Al-Rawi N, Al-Timimi J. Evaluation of foramen magnum in gender determination using helical CT scanning. Dentomaxillofacial Radiol. 2012; 41 (3): 197-202.

[14] Kamath VG, Asif M, Shetty R, Avadhani R. Binary Logistic Regression Analysis of Foramen Magnum Dimensions for Sex Determination. Anat Res Int. 2015 5; 2015e1-e9.

[15] Osunwoke E, Oladipo G. Morphometric analysis of the foramen magnum and jugular foramen in adult skulls in southern Nigerian population. Am J Sci Ind Res. 2012; 3 (6): 446-8.

[16] Ukoha U, Egwu O, Okafor I, Anyabolu A, Ndukwe G, Okpala I. Sexual Dimorphism in the Foramen Magnum of Nigerian Adult. Int J Biol Med Res. 2011; 2 (4): 878-81.

[17] Loyal P, Ogeti K, Mandela P, Ogeng'o J. Gender related patterns in the shapeand dimensions of the foramen magnum in adult kenyan population. Anat J Afr. 2013; 2 (2): 138-41.

[18] Moodley M, Rennie C, Lazarus L, Satyapal KS. The Morphometry and Morphology of the Foramen Magnum In Age And Sex Determination Within The South African Black Population Utilizing Computer Tomography (CT) Scans. Int J Morphol. 2019; 37 (1): 251-7.
[19] Zdilla M, Russell M, Bliss K, Mangus K, Koons A. The size and shape of the foramen magnum in man. J Craniovertebral Junction Spine. 2017; 8 (3): 205.

[20] Edwards K, Viner MD, Schweitzer W, Thali MJ. Sex determination from the foramen magnum. J Forensic Radiol Imaging. 2013; 1 (4): 186-92.

[21] İlgüy D, İlgüy M, Ersan N, Dölekoğlu S, Fişekçioğlu E. Measurements of the Foramen Magnum and Mandible in Relation to Sex Using CBCT. J Forensic Sci. 2014; 59 (3): 601-5.

[22] Durdan F, Szumito J, Walocha J, Klepacz L, Madej B, Dworzanki W. Morphology of the foramen magnum in young Eastern European adults. Folia Morphol. 2012; 71 (4): 20516.

[23] Gapert R, Black S, Last J. Sex determination from the foramen magnum: discriminant function analysis in an eighteenth and nineteenth century British sample. Int J Legal Med. 2009; 123 (1): 25-33.

[24] Madadin M, Menezes RG, Al Saif HS, Abu Alola H, Al Muhanna A, Gullenpet AH, et al. Morphometric evaluation of the foramen magnum for sex determination: A study from Saudi Arabia. J Forensic Leg Med. 2017; 46: 66-71.

[25] Spradley MK, Jantz RL. Sex Estimation in Forensic Anthropology: Skull Versus Postcranial Elements: Sex estimation in forensic anthropology. J Forensic Sci. 2011; 56 (2): 289-96. 